\title{
JURISPRUDENCIA AMBIENTAL DE LA UNIÓN EUROPEA (PRIMER SEMESTRE 2020)
}

\author{
ROSA GILES CARNERO \\ Profesora Titular de Derecho Internacional Público \\ Universidad de Huelva
}


Sumario: 1. Consideraciones introductorias. 2. Recursos por incumplimiento. 3. Cuestiones prejudiciales. 3.1. Aguas. 3.2. Conservación de los hábitats naturales y de la fauna y flora silvestres. 3.3. Evaluación impacto ambiental. 3.4. Residuos. 3.5. Garantía de recurso efectivo en materia de medio ambiente. 3.6. Principio de quien contamina paga.

\section{CONSIDERACIONES INTRODUCTORIAS}

En el período comprendido entre el 1 de octubre de 2019 y el 31 de marzo de 2020, el Tribunal de Justicia emitió doce sentencias en las que abordó diferentes asuntos en los que resultaba de aplicación el derecho ambiental europeo. En primer término, cabe enumerar las sentencias que se produjeron como resultado de procedimientos incoados por la Comisión Europea en el marco del artículo 258 TFUE, en relación con el incumplimiento por parte de Estados miembros de actos legislativos de la Unión Europea que tienen por objeto la protección del medio ambiente. El Tribunal de Justicia emitió tres sentencias en respuesta a recursos por incumplimiento, en las que se abordó la responsabilidad de España, Francia, y Chipre. En el caso contra España, el tribunal no admitió el recurso, mientras que en los restantes declaró el incumplimiento. A estos pronunciamientos, se suman dos sentencias emitidas en respuesta a recursos establecidos conforme al artículo 260.2 TFUE, mediante los que se valora el posible incumplimiento de sentencias anteriores del Tribunal de Justicia. En ambos casos, el resultado fue de condena, de forma que se declararía el incumplimiento de Irlanda y Grecia.

Asimismo, en el período examinado se dictaron siete sentencias en respuesta a peticiones de decisión prejudicial remitidas al Tribunal de Justicia por órganos jurisdiccionales nacionales, en relación con la interpretación de distintas disposiciones de contenido ambiental del derecho de la Unión Europea. Las cuestiones abordadas en estos pronunciamientos son diversas, y como viene siendo habitual en estas crónicas se han incluido en diferentes epígrafes que muestran las diferentes materias abordadas en las sentencias. En el primer epígrafe aparecen dos sentencias relativas a protección de aguas; el segundo incluye una sentencia sobre conservación de los hábitats naturales y de la fauna y flora silvestres; el tercer epígrafe introduce una sentencia relativas a la evaluación impacto ambiental; se añade un cuarto epígrafe en el que se incluye 
una sentencia sobre residuos; un quinto epígrafe se refiere a la garantía de recurso efectivo en materia de medio ambiente; y por último, aparece un apartado relativo a una sentencia sobre el principio de quien contamina paga.

\section{RECURSOS POR INCUMPLIMIENTO}

En el periodo comprendido en la presente crónica, se dictaron tres sentencias en respuesta a recursos interpuestos contra Estados miembros por el posible incumplimiento de normativa ambiental europea. En primer lugar y por orden cronológico, cabe citar la sentencia del Tribunal de Justicia de la Unión Europea (Sala Séptima) de 24 de octubre de 2019, as. C-636/186, Comisión Europea contra República Francesa, en la que se declaró el incumplimiento de diversos apartados de la Directiva 2008/50/CE, relativa a la calidad del aire ambiente y a una atmósfera más limpia en Europa1. La Directiva 2008/50/CE estableció valores límites de dióxido de nitrógeno (NO2) que entraron en vigor en 2010, y en este caso se pidió al Tribunal que se pronunciara sobre el posible incumplimiento por Francia de sus previsiones en relación a esta sustancia. En particular, la Comisión Europea argumentó que se había vulnerado su artículo 13.1 en relación al anexo XI, al superar "de manera sistemática y continuada" el valor límite anual de NO2 en doce aglomeraciones y zonas de calidad del aire, y el valor límite horario de NO2 en dos aglomeraciones y zonas de calidad del aire, en ambos casos desde el 1 de enero de 2010; y el artículo 23.1, en relación con el anexo XV, desde el 11 de junio del mismo año, al no "velar por que el período de superación sea lo más breve posible"2.

El Tribunal analizó los diferentes informes presentados sobre la calidad de aire en las zonas implicadas, y señaló que el hecho de que se superasen los valores límite de NO2 suponía en sí mismo que se había dado un incumplimiento, de forma que esta constatación objetiva hacía irrelevante "que tal incumplimiento resulte de la voluntad del Estado miembro, al que le sea imputable, de su negligencia o incluso de dificultades técnicas o estructurales a las que haya del aire ambiente y a una atmósfera más limpia en Europa, DO L 152, 11 de junio de 2008, p. 1.

2 Véase párrafo 1. 
tenido que hacer frente"3. Esta argumentación llevó al Tribunal a declarar el incumplimiento del artículo 13.1, en relación al anexo $\mathrm{XI}$, de la Directiva 2008/50/CE. Se dio por probado, de esta forma, que se habían superado los valores límite de NO2, ahora bien, el Tribunal precisó que esta constatación no podía, por sí misma, llevar a la conclusión de que también se había conculcado el artículo 23.1 de la Directiva4. El Tribunal declaró finalmente también el incumplimiento de este precepto, pero para ello, realizó un estudio pormenorizado del caso en el que pudo observarse la evolución de las medidas adoptadas, y la situación de contaminación ambiental que persistía en el tiempos.

En segundo lugar, cabe citar el pronunciamiento incluido en la sentencia del Tribunal de Justicia de la Unión Europea (Sala Octava) de 5 de diciembre de 2019, as. C-642/18, Comisión Europea contra España, en la que se consideró el posible incumplimiento de la Directiva 2008/98/CE, sobre residuos6. La Comisión Europea había solicitado la declaración de incumplimiento de los artículos 30.1 y 33.1 de esta Directiva, en relación a la revisión de los planes de gestión de residuos en las Comunidades Autónomas de Illes Balears y de Canarias, y al no haber sido informada oficialmente de la revisión de estos planes7. En este caso, el Tribunal declaró la inadmisión del recurso, debido a que apreció que la Comisión había iniciado prematuramente la fase administrativa previa del procedimiento del recurso por incumplimientos. La Comisión había comenzado este procedimiento antes de que finalizara el plazo de transposición de la Directiva, por lo que el Tribunal consideró que "dado que la obligación cuyo incumplimiento alega la Comisión no nació hasta después de la fecha de emisión del escrito de requerimiento, la Comisión, en efecto, no podía invocar válidamente incumplimiento alguno de la obligación prevista en el citado artículo 30, apartado 1", de forma que "estimar lo contrario supondría comprometer

\footnotetext{
3 Véanse párrafos 38 y 42.

4 Véase párrafo 80.

5 Véanse párrafos 82 y 87 y siguientes.

6 Directiva 2008/98/CE del Parlamento Europeo y del Consejo, de 19 de noviembre de 2008, sobre los residuos y por la que se derogan determinadas Directivas, DO, L 312, 22 de noviembre de 2008, p. 3.

7 Véase párrafo 1.

8 Véase párrafo 24.
} 
indefectiblemente las exigencias de seguridad jurídica inherentes a todo procedimiento que pueda culminar en un procedimiento judicial” 9.

Un tercer pronunciamiento relativo a normativa ambiental fue recogido en la sentencia del Tribunal de Justicia de la Unión Europea (Sala Sexta) de 5 de marzo de 2020, as. C-248/19, Comisión Europea contra República de Chipre, en la que se declaró el incumplimiento del artículo 3 y el punto A del Anexo I, de la Directiva 91/271/CEE, sobre el tratamiento de aguas residuales urbanas, modificada por el Reglamento (CE) no 1137/200810. En su argumentación, el Tribunal recordó que la obligación de disponer de sistemas de recogida de aguas residuales urbanas, es una obligación de resultado precisa, formulada de manera clara, y no inequívoca 11. En consecuencia, el Tribunal declaró el incumplimiento del Estado al omitir el establecimiento de un sistema de recogida de aguas residuales en 31 aglomeraciones urbanas, de forma que no se garantizase su tratamiento en los sistemas de recolección12.

A los pronunciamientos anteriores, se suman dos sentencias emitidas en respuesta a recursos establecidos conforme al artículo 260.2 TFUE, mediante los que se valora el posible incumplimiento de sentencias anteriores del Tribunal de Justicia. En primer término, y por orden cronológico, cabe citar el pronunciamiento incluido en la sentencia del Tribunal de Justicia de la Unión Europea (Gran Sala) de 12 de noviembre de 2019, as. C-261/18, Comisión Europea contra República de Irlanda, en la que se declaró el incumplimiento de la sentencia de 3 de julio de 2008, as. C-215/06. En el primer pronunciamiento se había declarado el incumplimiento de los artículos 2, 4 y 5 a 10, de la Directiva 85/337/CE, relativa a la evaluación de las repercusiones de determinados proyectos públicos y privados sobre el medio ambiente, en relación al desarrollo

\footnotetext{
9 Véanse párrafos 25 y 26.

10 Directiva 91/271/CEE del Consejo, de 21 de mayo de 1991, sobre el tratamiento de las aguas residuales urbanas, DO, L 135, 30 de mayo de 1999, p. 40; y Reglamento (CE) no 1137/2008 del Parlamento Europeo y del Consejo, de 22 de octubre de 2008 , por el que se adaptan a la Decisión 1999/468/CE del Consejo determinados actos sujetos al procedimiento establecido en el artículo 251 del Tratado, en lo que se refiere al procedimiento de reglamentación con control, DO, L 311, 21 de noviembre de 2008, p. 1.

11 Véase párrafo 27.

12 Véase párrafo 43.
} 
de un proyecto de parque eólico 13. Esta segunda sentencia constató que después de más de once años no se había procedido a una regularización mediante la que dar cumplimiento a la sentencia, de forma que se había producido un incumplimiento grave y se había conculcado la obligación de cooperación leal14. En consecuencia, el Tribunal señaló la obligación de Irlanda de abonar una "cantidad a tanto alzado de 1.343,20 euros multiplicada por el número de días transcurridos entre el pronunciamiento de la sentencia de 3 de julio de 2008, [...], y, bien la fecha de ejecución de dicha sentencia por Irlanda, bien la fecha de la sentencia dictada en el presente asunto si esta última es anterior a la fecha de ejecución de la sentencia de 3 de julio de 2008 [...], cantidad a tanto alzado que no deberá ser inferior a 1685000 euros", y "una multa coercitiva de 12.264 euros diarios a partir de la fecha de la sentencia dictada en el presente asunto y hasta la fecha en que Irlanda ejecute la sentencia de 3 de julio de 2008".

Unos meses después, se emitió la sentencia del Tribunal de Justicia de la Unión Europea (Sala Novena) de 27 de febrero de 2020, as. C-298/19, Comisión Europea contra República Helénica, en la que se declaró el incumplimiento de la sentencia de 23 de abril de 2015, as. C-149/14. En el primer pronunciamiento se consideraron vulnerados los artículos 4.4 y 5.1 de la Directiva 91/676/CEE, relativa a la protección de las aguas contra la contaminación causada por nitratos procedentes de fuentes agrícolas, al no haberse designado como áreas vulnerables las que incluían aguas superficiales y subterráneas afectadas por concentraciones de nitrato superiores a 50 miligramos por litro y por fenómenos de eutrofización, y al no haberse elaborado en plazo los programas requeridos 15. El Tribunal constató que no se habían tomado las medidas suficientes para el cumplimiento de la primera sentencia, y teniendo en cuenta el tiempo transcurrido, señaló que se había producido una vulneración grave del derecho

\footnotetext{
13 Directiva 91/676/CEE del Consejo, de 12 de diciembre de 1991, relativa a la protección de las aguas contra la contaminación producida por nitratos utilizados en la agricultura, DO, L 375, 31 de diciembre de 1991, p. 1

14 Véanse párrafos 118, 120 y 121.

15 Directiva 85/337/CEE del Consejo, de 27 de junio de 1985, relativa a la evaluación de las repercusiones de determinados proyectos públicos y privados sobre el medio ambiente, DO, L 175, 5 de julio de 1985, p. 40; Directiva 97/11/CE del Consejo, de 3 de marzo de 1997, DO, L 73, de 14 de marzo de 1997, p. 5.
} 
ambiental16. En consecuencia, el Tribunal estableció la obligación del Estado de pagar una suma global de 3.500 .000 de euros por este incumplimiento.

\section{CUESTIONES PREJUDICIALES}

\subsection{Aguas.}

En el periodo comprendido en la presente crónica, el Tribunal de Justicia resolvió dos asuntos en los que se plantearon cuestiones prejudiciales relacionadas con los sistemas de protección de aguas. En primer término, cabe señalar la sentencia del Tribunal de Justicia (Sala Primera) de 3 de octubre de 2019, as. C-197/18, Mancomunidad de Aguas de Burgenland Norte y otros contra Ministerio Federal de Sostenibilidad y Turismo (Austria), en la que se resolvió una cuestión prejudicial planteada por el Tribunal de lo ContenciosoAdministrativo de Viena sobre la interpretación del artículo 288 TFUE y de la Directiva 91/676/CEE, relativa a la protección de las aguas contra la contaminación producida por nitratos procedentes de fuentes agrarias 17. En particular, en el procedimiento principal se cuestionaba la decisión del Ministerio Federal de Sostenibilidad y Turismo, de 30 de mayo de 2016, en la que se declaró la inadmisibilidad de solicitudes de modificación y revisión del Reglamento relativo al Programa de Acción Nitratos de 2012.

El órgano jurisdiccional nacional cuestionó si la interpretación del artículo 288 TFUE, y los apartados cuarto y quinto del artículo 5, y la letra A.2 del Anexo I de la Directiva 91/676, podría dar lugar a considerar que las personas físicas y jurídicas, responsables del suministro de agua o autorizadas para utilizar una fuente, deben tener la facultad de exigir a las autoridades nacionales que modifiquen un programa de acción o adopten medidas adicionales de forma que se asegure una concentración máxima en nitratos de $50 \mathrm{mg} / \mathrm{l}$ en cada punto de extracción de agua, lo que conllevaría reconocer la legitimación de los

16 Véanse párrafos 26 y 52.

17 Directiva 91/676/CEE del Consejo, de 12 de diciembre de 1991, relativa a la protección de las aguas contra la contaminación producida por nitratos procedentes de fuentes agrarias, DO, L 375, 31 de diciembre de 1991, p. 1. 
particulares para reclamar este objetivo ante autoridades y tribunales 18 . Como respuesta a esta cuestión, el Tribunal declaró que, si el vertido de compuestos nitrogenados de origen agrario contribuye significativamente a la contaminación de las aguas subterráneas, debe considerarse que las personas físicas y jurídicas responsables del suministro de agua o autorizadas para utilizar una fuente, tienen la "facultad de exigir a las autoridades nacionales competentes que modifiquen un programa de acción existente o que adopten las medidas adicionales o acciones reforzadas contempladas en el artículo 5, apartado 5, de esa Directiva por tanto tiempo como el contenido en nitratos en las aguas subterráneas sobrepase los $50 \mathrm{mg} / \mathrm{l}$ o exista el riesgo de que en ausencia de tales medidas los sobrepase, en uno o en varios puntos de medición, en el sentido del artículo 5, apartado 6, de dicha Directiva" 19.

En segundo lugar, cabe señalar la sentencia del Tribunal de Justicia (Sala Quinta) de 7 de noviembre de 2019, as. C-105 a 113/18, Asociación Española de la Industria Eléctrica (UNESA) y otros contra Administración General del Estado (España), relativa a la acumulación de varias cuestiones prejudiciales planteadas por el Tribunal Supremo español sobre la interpretación de los artículos 107.1 y 191.2 TFUE, del artículo 9.1 de la Directiva 2000/60/CE, por la que se establece un marco comunitario de actuación en el ámbito de la política de aguas; y del artículo 3.1 de la Directiva 2009/72/CE, sobre normas comunes para el mercado interior de la electricidad20. En el litigio principal los recurrentes solicitaron la anulación del Real Decreto 198/2015, por el que se desarrolla el artículo 112 bis del texto refundido de la Ley de Aguas, el cual regula el canon por la utilización de las aguas continentales para la producción de energía eléctrica en las demarcaciones hidrográficas situadas en el territorio de más de una comunidad autónoma21. El canon en cuestión fue introducido en la Ley de Aguas por las prescripciones de la Ley fiscal de la energía, y el Tribunal Supremo

18 Véanse párrafos 28 y 29.

19 Véase párrafo 73.

20 Directiva 2000/60/CE del Parlamento Europeo y del Consejo, de 23 de octubre, DO, L 327, 22 de diciembre de 2000, p. 1; y Directiva 2009/72/CE del Parlamento Europeo y del Consejo, de 13 de julio de 2009 , sobre normas comunes para el mercado interior de la electricidad y por la que se deroga la Directiva 2003/54/CE, DO, L 211, 14 de agosto de 2009, p. 55.

21 Véase párrafo 16. 
señaló sus dudas sobre la compatibilidad de estas últimas prescripciones con "el principio de que quien contamina paga, consagrado en el artículo 191 TFUE, apartado 2, en relación con la Directiva 2000/60; en segundo lugar, con el principio de no discriminación consagrado en el artículo 3, apartado 1, de la Directiva 2009/72, y, en tercer lugar, con el Derecho de la competencia, y pregunta a este respecto si dicho canon puede considerarse una ayuda de Estado a efectos del artículo 107 TFUE, apartado 1"22.

El Tribunal de Justicia analizaría el caso concreto, y concluiría señalando diferentes aspectos interpretativos. En primer término, el Tribunal declaró que "el artículo 191 TFUE, apartado 2, y el artículo 9, apartado 1, de la Directiva 2000/60 deben interpretarse en el sentido de que no se oponen a un canon por la utilización de las aguas continentales para la producción de energía como el controvertido en los litigios principales, que no incentiva el uso eficiente del agua, ni establece mecanismos para la conservación y protección del dominio público hidráulico, y cuya cuantificación se desvincula totalmente de la capacidad de producir daños al dominio público, centrándose única y exclusivamente en la capacidad de generar ingresos de los productores de energía hidroeléctrica23. A lo señalado añadió que "el principio de no discriminación, establecido en el artículo 3, apartado 1, de la Directiva 2009/72, debe interpretarse en el sentido de que no se opone a un canon como el canon por la utilización de las aguas continentales para la producción de energía eléctrica controvertido en los litigios principales, que solo recae sobre los generadores de energía hidroeléctrica que operan en cuencas situadas en el territorio de más de una comunidad autónoma" 24.

En tercer término, el Tribunal declaró que "el artículo 107 TFUE, apartado 1, debe interpretarse en el sentido de que el hecho de que el canon por la utilización de las aguas continentales para la producción de energía eléctrica controvertido en los litigios principales no recaiga, por una parte, sobre los productores de energía hidroeléctrica que operan en cuencas hidrográficas situadas en el

\footnotetext{
22 Véase párrafo 18.

23 Véase párrafo 45.

24 Véase párrafo 54.
} 
territorio de una única comunidad autónoma y, por otra parte, sobre los productores de energía eléctrica procedente de fuentes diferentes de la hidráulica no constituye una ayuda de Estado en el sentido de esta disposición en favor de esos productores, ya que estos últimos no se encuentran, habida cuenta del marco de referencia pertinente y del objetivo perseguido por el canon, en una situación comparable a la de los productores de energía hidroeléctrica que operan en cuencas hidrográficas situadas en el territorio de más de una comunidad autónoma sujetos a dicho canon, extremo este que corresponde comprobar al órgano jurisdiccional remitente" 25.

\subsection{Conservación de los hábitats naturales y de la fauna y flora silvestres.}

En el período temporal fijado por esta crónica, el Tribunal de Justicia de la Unión Europea resolvió una cuestión prejudicial relativa a la interpretación de normativa europea en materia de conservación de los hábitats naturales, y de la fauna y flora silvestres. Mediante la sentencia del Tribunal de Justicia de la Unión Europea (Sala Segunda) de 10 de octubre de 2019, as. C-674/17, Luonnonsuojeluyhdistys Tapiola Pohjois-Savo- Kainuu ry contra Instituto Finlandés de la Fauna Salvaje, se resolvió una pregunta planteada por el Tribunal Supremo de lo Contencioso-Administrativo de Finlandia, sobre la interpretación de la Directiva 92/43/CEE, relativa a la conservación de los hábitats naturales y de la fauna y flora silvestres (Directiva Hábitats) 26. En particular, en esta cuestión prejudicial se requirió al Tribunal de Justicia que desarrollase la interpretación del artículo 16.1.e) de la Directiva Hábitats, relativo a la excepción que permite la toma de un número limitado de determinados especímenes, en relación con la legalidad de varias decisiones del Instituto Finlandés de la Fauna Salvaje que aplicaban estas excepciones para la caza del lobo.

El lobo es una especie especialmente amenazada en Finlandia, y ante las autorizaciones de caza que originaron el litigio principal, el órgano jurisdiccional naturales y de la fauna y flora silvestres, DO, L 206, 22 de julio de 1992, p. 7. 
nacional presentó su pregunta sobre la compatibilidad del artículo 16.1.e) de la Directiva Hábitats, con unas excepciones a la prohibición del sacrificio deliberado del lobo establecidas mediante la caza de gestión y para luchar contra la caza furtiva27. En respuesta a la cuestión planteada, el Tribunal declaró que este precepto debía interpretarse "en el sentido de que se opone a la adopción de decisiones por las que se conceden excepciones a la prohibición del sacrificio deliberado del lobo [...]- en virtud de la caza de gestión y cuyo objetivo es la lucha contra la caza furtiva, si: - el objetivo perseguido por tales excepciones no está fundamentado de manera clara y precisa y si, a la vista de datos científicos rigurosos, la autoridad nacional no puede acreditar que dichas excepciones sean idóneas para alcanzar el mencionado objetivo; - no se ha acreditado debidamente que el objetivo que tales excepciones persiguen no pueda alcanzarse mediante otra solución satisfactoria, puesto que la mera existencia de una actividad ilegal o las dificultades a las que se enfrenta el control de esta última no pueden constituir un elemento suficiente a este respecto; - no se garantiza que las excepciones no perjudican el mantenimiento, en un estado de conservación favorable, de las poblaciones de la especie de que se trate en su área de distribución natural; - las excepciones no han sido objeto de una evaluación sobre el estado de conservación de las poblaciones de la especie de que se trate, así como sobre la repercusión que la excepción prevista puede tener en tal estado de conservación, en el territorio de ese Estado miembro o, en su caso, en la región biogeográfica contemplada cuando las fronteras de dicho Estado miembro incluyan varias regiones biogeográficas o, incluso, si el área de distribución natural de la especie lo exige y, en la medida de lo posible, en el plano transfronterizo, y; - no se cumplen todos los requisitos relativos al criterio selectivo y a la forma limitada de las tomas de un número limitado y especificado de determinados especímenes de las especies que figuran en el anexo IV de dicha Directiva en condiciones de riguroso control, cuya observancia debe acreditarse teniendo en cuenta, en particular, el nivel de la población, su estado de conservación y sus características biológicas" 28 . 


\subsection{Evaluación impacto ambiental.}

En el período analizado en esta crónica, el Tribunal de Justicia emitió una sentencia que respondía a una cuestión prejudicial relativa a la interpretación de la normativa europea sobre evaluación de impacto ambiental. La sentencia del Tribunal de Justicia de la Unión Europea (Sala Primera) de 7 de noviembre de 2019, as. C-280/18, Alain Flausch y otros contra Ypourgos Perivallontos kai Energeias y otros, resolvió una cuestión prejudicial planteada por el Consejo de Estado de Grecia, en la que se planteó la interpretación de los artículos 6 y 11 de la Directiva 2011/92/UE, relativa a la evaluación de las repercusiones de determinados proyectos públicos y privados sobre el medio ambiente29. El litigio principal tenía como objeto valorar la legalidad de la autorización de la construcción de un complejo turístico en la isla de ĺos, en Grecia, y para ello el órgano jurisdiccional nacional trasladó dos cuestiones al Tribunal de Justicia sobre la interpretación de la Directiva 2011/92/UE.

En su primera cuestión, el órgano jurisdiccional nacional preguntó si el artículo 6 de la Directiva es compatible con una actuación nacional que desarrolle la participación del público en la toma de decisiones relativas a un proyecto en la región competente, y no a nivel de la unidad municipal en la que se ubica el proyecto30. Para responder a esta cuestión, el Tribunal recordó que el artículo 6.5 de la Directiva 2011/92/UE "reserva expresamente a los Estados miembros el derecho a determinar las modalidades precisas de información y consulta del público interesado", "[...] siempre que no sean menos favorables que los que regulan situaciones similares de carácter interno (principio de equivalencia) y no hagan imposible en la práctica o excesivamente difícil el ejercicio de los derechos conferidos por el ordenamiento jurídico de la Unión (principio de efectividad)"31. Teniendo en cuenta estos presupuestos, y atendiendo a las circunstancias particulares del caso, el Tribunal declaró que "procede responder a la primera

29 Directiva 2011/92/UE del Parlamento Europeo y del Consejo, de 13 de diciembre de 2011, relativa a la evaluación de las repercusiones de determinados proyectos públicos y privados sobre el medio ambiente, DO, L 26, 28 de enero de 2012, p. 1.

30 Véase párrafo 25.

31 Véanse párrafos 26 y 27. 
cuestión que el artículo 6 de la Directiva EIA debe interpretarse en el sentido de que se opone a que un Estado miembro lleve a cabo operaciones de participación del público en el proceso de toma de decisiones relativas a un proyecto a nivel de la autoridad administrativa regional competente, y no a nivel de la unidad municipal en la que esté situado el proyecto, cuando las modalidades prácticas aplicadas no garanticen el respeto efectivo de los derechos del público interesado, lo que corresponde comprobar al órgano jurisdiccional nacional"32.

Teniendo en cuenta la respuesta que podría obtener la primera cuestión, el órgano jurisdiccional nacional incluyó una segunda, en la que se preguntó si la interpretación de los artículos 9 y 11 de la Directiva se oponía a una normativa que establecía que el plazo de 60 días otorgado para interponer un recurso, comenzaba a partir del anuncio de la aprobación de una obra en un sitio webзз. También aquí se recuerda que la Directiva reservó a los Estados miembros la capacidad de establecer la normativa sobre el inicio y cómputo de los plazos, y se destaca la importancia de que esta normativa sea acorde con los principios de equivalencia y eficacia34. El Tribunal analizó las circunstancias concretas del caso, y argumentó que si bien, en principio, no parece un obstáculo excesivo que el inicio del cómputo dependa de una publicación, el elemento decisivo resulta si el acceso a ésta resulta adecuado, y no es obstaculizado por las autoridades35. En consecuencia, el Tribunal de Justicia declaró que "procede responder a la segunda cuestión que los artículos 9 y 11 de la Directiva EIA deben interpretarse en el sentido de que son contrarios a una normativa, como la controvertida en el litigio principal, que da lugar a que se oponga un plazo, para que los miembros del público interesado interpongan un recurso, cuyo cómputo se inicia a partir del anuncio en Internet de la autorización de un proyecto, cuando dichos miembros del público interesado no hayan tenido previamente la oportunidad adecuada de

\footnotetext{
32 Véase párrafo 44.

33 Véase párrafo 45.

34 Véase párrafo 51.

35 Véanse párrafos 55 y 56.
} 
informarse sobre el procedimiento de autorización de conformidad con el artículo 6, apartado 2, de dicha Directiva"36.

\subsection{Residuos.}

En este apartado se incluye una sentencia relativa a la normativa europea en materia de residuos. La sentencia del Tribunal de Justicia de la Unión Europea (Sala Segunda) de 24 de octubre de 2019, as. C-212/18, Prato Nevoso Termo Energy Srl contra Provincia di Cuneo y otros, resolvió una cuestión prejudicial planteada por el Tribunal Regional de lo Contencioso-Administrativo de Piamonte (Italia), en la que se preguntó sobre la interpretación del artículo 6 de la Directiva 2008/98/CE, sobre residuos, y del artículo 13 de la Directiva 2009/28/CE, relativa al fomento del uso de energía procedente de fuentes renovables37. El litigio principal que produjo este pronunciamiento tenía como objeto la desestimación de una solicitud presentada por una empresa italiana para sustituir el metano por biolíquido obtenido a partir del tratamiento químico de aceites vegetales usados, como fuente de alimentación de su central de producción de energía térmica y eléctrica.

El órgano jurisdiccional cuestionó si la interpretación conjunta de los preceptos señalados se opone a una normativa nacional que "en virtud de la cual una solicitud de autorización para sustituir, como fuente de alimentación de una instalación de producción de energía eléctrica que produce emisiones atmosféricas, el metano por una sustancia derivada del tratamiento químico de aceites vegetales usados, como la controvertida en el litigio principal, debe desestimarse, debido a que esta última no ha sido incluida en la lista de las categorías de combustibles procedentes de la biomasa autorizados a tal efecto y a que esa lista solo puede modificarse mediante un acto interno de alcance

\footnotetext{
36 Véase párrafo 60.

37 Directiva 2008/98/CE del Parlamento Europeo y del Consejo, de 19 de noviembre de 2008, sobre los residuos y por la que se derogan determinadas Directivas, DO, L 312, 22 de noviembre de 2008, p. 3; Directiva 2009/28/CE del Parlamento Europeo y del Consejo, de 23 de abril de 2009, relativa al fomento del uso de energía procedente de fuentes renovables y por la que se modifican y se derogan las Directivas 2001/77/CE y 2003/30/CE, DO, L 140, 5 de junio de 2009, p. 16, en su versión modificada por la Directiva (UE) 2015/1513 del Parlamento Europeo y del Consejo, de 9 de septiembre de 2015, DO, L 239, 15 de septiembre de 2015, p. 1
} 
general cuyo procedimiento de adopción no está coordinado con el procedimiento administrativo de autorización de la utilización de una sustancia procedente de la biomasa como combustible" 38. El Tribunal valoró las circunstancias del caso para delimitar las condiciones en las que debía considerarse que las sustancias implicadas podían perder la calificación de residuos, y ser calificados como combustibles 39.

Conforme al examen desarrollado, el Tribunal respondió a la cuestión planteada declarando que "el artículo 6, apartados 1 y 4, de la Directiva 2008/98 y el artículo 13, apartado 1, de la Directiva 2009/28, leídos conjuntamente, deben interpretarse en el sentido de que no se oponen a una normativa nacional en cuya virtud una solicitud de autorización para sustituir, como fuente de alimentación de una instalación destinada a la producción de energía eléctrica que produce emisiones atmosféricas, el metano por una sustancia derivada del tratamiento químico de aceites vegetales usados debe denegarse, debido a que esa sustancia no ha sido incluida en la lista de categorías de combustibles procedentes de la biomasa autorizados a tal efecto y a que esa lista solo puede modificarse mediante un decreto ministerial cuyo procedimiento de adopción no está coordinado con el procedimiento administrativo de autorización de la utilización de esa sustancia como combustible, si el Estado miembro ha podido considerar, sin incurrir en error manifiesto de apreciación, que no ha quedado demostrado que la utilización del aceite vegetal cumpla, en esas circunstancias, los requisitos exigidos en el artículo 6, apartado 1, de la Directiva 2008/98 y, en particular, carezca de posible efecto adverso alguno sobre el medio ambiente y la salud humana. Incumbe al órgano jurisdiccional remitente comprobar si sucede así en el asunto principal" 40.

\subsection{Garantía de recurso efectivo en materia de medio ambiente.}

\footnotetext{
38 Véase párrafo 29.

39 Véanse párrafos 41 y siguientes.

40 Véase párrafo 59.
} 
En el período analizado en esta crónica, el Tribunal de Justicia emitió una sentencia en la que incluyó algunas argumentaciones en torno a la garantía de recurso efectivo en materia de medio ambiente. La sentencia del Tribunal de Justicia de la Unión Europea (Gran Sala) de 19 de diciembre de 2019, as. C752/18, Deutsche Umwelthilfe eV contra Freistaat Bayern, resolvió una cuestión prejudicial planteada por el Tribunal Superior de lo Contencioso-Administrativo de Baviera (Alemania), que tuvo como objeto la interpretación del artículo 9.4 del Convenio de Aarhus, de los artículos 4.3 y 19 TUE, artículo 197.1 TFUE, y del artículo 47.1 de la Carta de los Derechos Fundamentales de la Unión Europea41. El litigio principal se había originado por la ejecución forzosa de una orden conminatoria por la que un tribunal exigía al Estado Federado de Baviera que estableciera determinadas prohibiciones de circulación de vehículos en cumplimiento de la Directiva 2008/50/CE, relativa a la calidad del aire ambiente y a una atmósfera más limpia en Europa42.

El órgano jurisdiccional nacional cuestionó, en este caso, si el Derecho de la Unión "debe interpretarse en el sentido de que, en una situación caracterizada por la negativa persistente de una autoridad nacional a dar cumplimiento a una resolución judicial que la conmina a ejecutar una obligación clara, precisa e incondicional derivada de dicho Derecho, en particular de la Directiva 2008/50, el Derecho de la Unión faculta al tribunal nacional competente para imponer un arresto coercitivo a titulares de una función que implica el ejercicio del poder público, o incluso le obliga a hacerlo" 43. Para responder a esta pregunta, el Tribunal de Justicia recordó que no se ha producido una armonización de los mecanismos nacionales de ejecución forzosa, por lo que las modalidades de aplicación quedan dentro del principio de autonomía procesal de los Estados miembros. No obstante, esta afirmación debe matizarse por el principio de equivalencia, que conlleva la exigencia de que no se establezcan modalidades

\footnotetext{
${ }_{41}$ Convenio sobre el Acceso a la Información, la Participación del Público en la Toma de Decisiones y el Acceso a la Justicia en Materia de Medio Ambiente, hecho en Aarhus (Dinamarca) el 25 de junio de 1998 y aprobado en nombre de la Comunidad Europea por la Decisión 2005/370/CE del Consejo, de 17 de febrero de 2005, DO, L 124, 17 de mayo de 2005, p. 1. del aire ambiente y a una atmósfera más limpia en Europa, DO, L 152, 11 de junio de 2008, p. 1.
}

43 Véase párrafo 29. 
menos favorables que las que rigen situaciones similares sometidas a Derecho interno; y por el principio de efectividad, de forma que no puedan hacer imposible o excesivamente difícil el ejercicio de tales derechos 44 . A estas afirmaciones el Tribunal de Justicia agregó la importancia de recordar la obligación de los Estados miembros de garantizar el respeto al derecho a la tutela judicial efectiva cuando se aplique Derecho Ambiental de la Unión, y que, conforme a su jurisprudencia, se vulnera este derecho cuando una normativa nacional conduce a que una resolución de un tribunal quede inoperante 45.

Teniendo en cuenta estas consideraciones, y tras analizar las circunstancias concretas del caso, el Tribunal de Justicia declaró que "procede responder a la cuestión planteada que el Derecho de la Unión, en particular el artículo 47, párrafo primero, de la Carta, debe interpretarse en el sentido de que, en una situación caracterizada por la negativa persistente de una autoridad nacional a dar cumplimiento a una resolución judicial que la conmina a ejecutar una obligación clara, precisa e incondicional derivada de dicho Derecho, en particular de la Directiva 2008/50, incumbe al tribunal nacional competente imponer un arresto coercitivo a titulares de una función que implica el ejercicio del poder público cuando en las disposiciones del Derecho interno exista una base legal para la imposición de tal arresto que sea suficientemente accesible, precisa y previsible en su aplicación, y siempre que la limitación del derecho a la libertad, garantizado por el artículo 6 de la Carta, que ese arresto supondría satisfaga los demás requisitos establecidos al respecto en el artículo 52, apartado 1, de la Carta. En cambio, de no existir una base legal de tales características en el Derecho interno, el Derecho de la Unión no faculta a ese tribunal para que recurra a dicha medida" 46 .

\subsection{Principio de quien contamina paga.}

44 Véase párrafo 33.

45 Véanse párrafos 34 y 35.

46 Véase párrafo 56. 
En este apartado se incluye una sentencia en la que el Tribunal de Justicia abordó la interpretación del principio de quien contamina paga, en relación a su aplicación en el ámbito del mercado interior de la energía. La sentencia del Tribunal de Justicia de la Unión Europea (Sala Quinta) de 7 de noviembre de 2019, as. C-80 a 83/18, Asociación Española de la Industria Eléctrica (UNESA) y otros contra Administración General del Estado, resolvió cuatro cuestiones prejudiciales planteadas por el Tribunal Supremo español relativas a la interpretación del artículo 191.2 TFUE, de los apartados 1 y 2 del artículo 3 de la Directiva 2009/72/CE, sobre normas comunes para el mercado interior de la electricidad; de los artículos 3 y 5 de la Directiva 2005/89/CE, sobre las medidas de salvaguarda de la seguridad del abastecimiento de electricidad y la inversión en infraestructura, y de los artículos 20 y 21 de la Carta de los Derechos Fundamentales de la Unión Europea 47. El litigio principal que produjo este pronunciamiento vino motivado por el cuestionamiento de la legalidad de los impuestos sobre la energía nuclear, es decir, aquellos previstos sobre la producción de combustible nuclear gastado y de residuos radioactivos resultantes de la generación de energía nucleoeléctrica y sobre el almacenamiento de dichos combustible y residuos en instalaciones centralizadas.

El órgano jurisdiccional nacional introdujo dos preguntas, que el Tribunal de Justicia respondió conjuntamente, y que se referían a la interpretación de los artículos 20 y 21 de la Carta, y el artículo 3.1 de la Directiva 2009/72. La cuestión es si estos preceptos son contrarios a una normativa nacional, "como la controvertida en los asuntos principales, que establece impuestos a la producción y el almacenamiento de combustible y de residuos nucleares, que solo gravan a las empresas de generación de electricidad que utilizan energía nuclear, y cuyo objetivo principal no consiste en proteger el medio ambiente, sino en incrementar el volumen de ingresos del sistema financiero de la energía

47 Directiva 2009/72/CE del Parlamento Europeo y del Consejo, de 13 de julio de 2009, sobre normas comunes para el mercado interior de la electricidad y por la que se deroga la Directiva 2003/54/CE, DO, L 211, 14 de agosto de 2009, p. 55; Directiva 2005/89/CE del Parlamento Europeo y del Consejo, de 18 de enero de 2006, sobre las medidas de salvaguarda de la seguridad del abastecimiento de electricidad y la inversión en infraestructura, DO, L 33, 4 de febrero de 2006, p. 22. 
eléctrica" 48. Para responder a estas cuestiones, el Tribunal fundamentó su argumentación principalmente en la consideración de que la Directiva 2009/72 no constituye una medida relativa a la aproximación de las disposiciones fiscales de los Estados miembros, de forma que no se consideraría aplicable el principio de no discriminación y, en consecuencia, se declaró que no se opone a una normativa nacional sobre impuestos como la analizada en el litigio principal49.

A lo señalado hay que añadir que el Tribunal Supremo había añadido una tercera pregunta, mediante a la cual se cuestionó si debe considerarse que el artículo 3.2 de la Directiva 2009/72 es contrario a "una normativa nacional, como la controvertida en los litigios principales, cuando el objetivo medioambiental y las características de los impuestos medioambientales previstos por la misma no se materializan en la parte vinculante de esta normativa”. También en este aspecto, y siguiendo la misma argumentación, el Tribunal de Justicia declaró que los preceptos europeos no oponían a esta normativa nacional50.

Conforme a lo señalado, el Tribunal de Justicia concluyó su sentencia declarando que "[e]l principio de no discriminación, previsto en el artículo 3 , apartado 1, de la Directiva 2009/72/CE del Parlamento Europeo y del Consejo, de 13 de julio de 2009, sobre normas comunes para el mercado interior de la electricidad y por la que se deroga la Directiva 2003/54/CE, debe interpretarse en el sentido de que no se opone a una normativa nacional que establece impuestos sobre la producción y el almacenamiento de combustible y de residuos nucleares, como es el caso de los impuestos sobre la energía nuclear objeto de los litigios principales, que solo gravan a las empresas de generación de electricidad que utilizan energía nuclear, y cuyo objetivo principal no consiste en proteger el medio ambiente, sino en incrementar el volumen de ingresos del sistema financiero de la energía eléctrica"; a lo que añadió que "[e]l artículo 3, apartado 2, de la Directiva 2009/72 debe interpretarse en el sentido de que no se opone a una normativa nacional, como la controvertida en los litigios principales, cuando el objetivo medioambiental y las características de los

\footnotetext{
48 Véase párrafo 44.

49 Véanse párrafos 51 y 54.

50 Véanse párrafos 55 y 57.
} 
impuestos medioambientales previstos por la misma no encuentran concreción en la parte vinculante de esta normativa". 